\title{
Evaluation of sociodemographic factors and outcome associated with anaemia and its mode of correction in anaemic women (antenatal and non-antenatal) admitted in obstetrics and gynaecology department of tertiary care centre
}

\author{
Manideepa Roy, Geeta Chauhan \\ Corresponding author: Dr. Geeta Chauhan, Post Graduate Student, Department of Obstetrics and \\ Gynaecology, Fakhruddin Ali Ahmed Medical College, Barpeta, Assam, India; Email : \\ geetachauhan708501@gmail.com
}

Distributed under Attribution-Non Commercial - Share Alike 4.0 International (CC BY-NC-SA 4.0)

\begin{abstract}
Objective: The aim of the study was to evaluate sociodemographic factors and outcome asassociated with anemia and its mode of correction. Materials and methods: A hospital-based cross sectional study of 200 anemic women of all age group was conducted in the department of obstetrics and gynecologyof FAAMCH Barpeta from June 2019 to August 2019. Cases were selected consecutively and data were collected employing the interviewer-administered questionnaire after obtaining consent from participants. The result was analysed and presented using tables. Descriptive statistics were computed with percentages and proportions, chi square test. Variables with $\mathrm{p}$ value $<0.05$ were considered statistically significant. Results: A total of 200 anemic women were included in the study. $70 \%$ were antenatal cases, 30\% non antenatal. Majority of the cases were less than 20 yrs of age. More than 80 cases were married at early age and had 1 child before 20 years of age. Using multivariate analysis, the sociodemographic factors like age, age at marriage, age at first child birth $(p<0.0001)$, illiteracy $(p<0.0017)$, multiparity $(p<0.0029)$ showed a significant association with risk of anaemia $(p<0.05)$. Moderate degree of anaemia mainly found in pregnant women. On the other hand, non pregnant women mostly presented with severe anaemia. Among pregnant women, $47 \%$ of cases are not able to attend a single antenatal visit. Regarding outcome of pregnancy, 22 cases (out of 140 antenatal) associated with prematurity, 64 cases with low birth weight, and 18 cases with early neonatal death. Out of 200 cases, 7 maternal deaths were noted. Most of the women (95\%) undergone anaemia correction in which parenteral iron therapy followed by blood transfusion was the main mode of anaemia correction in antenatal cases and blood transfusion in non antenatal cases, (5\%) include incomplete or no correction. Conclusion: In our study, sociodemographic factors like age, age at marriage, age at first childbirth, illiteracy, obstetrical data like multiparity, were significantly associated with risk of anaemia $(\mathrm{p}<0.05)$. Moderate to severe anaemia was more prevalent. Based on our findings, there is a need of more anaemia awareness programmes and nutritional interventions to prevent fetomaternal complications.
\end{abstract}

Keywords: Evaluation, prevalence, anaemia, outcome, correction.

According to $\mathrm{WHO}^{1}$, anaemia is a condition in which the number and size of red blood cells or the haemoglobin concentration falls below established cut of value, consequently impairing the capacity of the blood to transport oxygen in the body. Anaemia is an indicator of both poor nutrition and poor health. Its prominence is worldwide, affecting 1.62 million people, of which 56 million are pregnant women ${ }^{1}$.

Women are especially likely to develop anaemia (most commonly iron deficiency) for several reasons. First, women

Received: $27^{\text {th }}$ January 2020, Peer review completed: $10^{\text {th }}$ July 2020, Accepted: $16^{\text {th }}$ July 2020.

Roy M, Chauhan G. Evaluation of sociodemographic factors and outcome associated with anaemia and its mode of correction in anaemic women (antenatal and non-antenatal) admitted in obstetrics and gynaecology department of tertiary care centre. The New Indian Journal of OBGYN. 2021; 7(2): 237-40. 
aged 12 to 49 lose blood approximately once a month during menses. Iron is needed to make the new blood that replaces the blood lost with each menstrual period. The risk of anaemia is higher among women with menstrual abnormalities like menorrhagia. Second, women need extra iron during pregnancy for the proper development of their babies. Women also lose blood during childbirth.

Anaemia lead to adverse fetomaternal outcomes in pregnancy like preterm birth, low birth weight, still birth, maternal and neonatal mortality. It also causes adverse effect in non pregnant women like, infection, menstrual irregularities, heart diseases, mental instability, and depression. India has been and continues to be a country with high prevalence of anaemia in the world. India is a home to the largest number of anaemia people in the world (WHO $2015)^{2}$. According to WHO $(2016)^{3}$ prevalence of anaemia among children is 58.6, pregnant women 50.4, non pregnant 53.2. Among reproductive age group (15-49yr) it is 51.40 (2016). According to NFHS $-4^{4,5}$ prevalence of anaemia is 50.3 .

Anaemia is considered as a major health problem in India, especially among women and children. The increase risk of anaemia is due to nutritional deficiency, poverty, poor quality of care. Many studies reveal that anaemia most commonly iron deficiency anaemia among women and mainly among pregnant women are the cause of maternal and neonatal morbidity and mortality. Evaluating the prevalence, associated factors and outcome may help in the interventions to lessen the burden of anaemia.

In India, ${ }^{6,7}$ Assam is the highest prevailing state constituting $72 \%$ among women aged $15-49$, besides, it is important to know variations in severity of anaemia among women, including the possible determinants and outcomes. Considering the above statement it is important to evaluate the associated sociodemographic factors, outcome during intranatal, postnatal, post abortion, heavy menstrual bleeding, in all anaemic women of all age group and its mode of correction at FAAMCH Barpeta.

\section{Materials and methods}

This hospital based cross sectional study was undertaken at obstetrics and gynaecology department of Fakhruddin Ali Ahmed medical college and hospital, Barpeta Assam from June 2019 to August 2019. Cases were selected consecutively fulfilling the inclusion and exclusion criteria till sample size are reached, and data were collected employing the interviewer-administered questionnaire after obtaining consent from participants. WHO guidelines were used to define and classify anaemia as mild, moderate, severe in both antenatal and non-antenatal cases. According to $\mathrm{WHO}$, in pregnant woman cut off value of haemoglobin is $(<11 \mathrm{gm} / \mathrm{dl})$, and in non-pregnant $(<12 \mathrm{gm} / \mathrm{dl}){ }^{10}$. Questions regarding age, age at marriage, age at first childbirth, parity, number of antenatal visits, use of contraception were asked.

Sample size was estimated by using the following formula: $\mathrm{N}=\mathrm{Z}^{2} * \mathrm{P}(1-\mathrm{P}) / \mathrm{D}^{2}$; Where $\mathrm{N}$ is estimated minimum sample size; $\mathrm{Z}$ is confidence level at $95 \%$; $\mathrm{P}$ is proportion (prevalence of anaemia in women (15-49yr) is 69.7, NFHS3) ${ }^{8,9}$, taking prevalence into account and permissible level of error as $10 \%$ the sample size for the study was 170 . We took 200 cases for our study.

Inclusion criteria: Anaemic women (antenatal and nonantenatal) admitted in obstetrics and gynaecology department were included.

Exclusion criteria: Women with bleeding disorders, heart diseases, hypertension, diabetes mellitus, $\mathrm{Rh}$ negative mother, preeclampsia, eclampsia, antepartum haemorrhage malaria, tuberculosis, any chronic illness.

The collected data was tabulated and analysed. Descriptive statistics were computed with percentages and chi-square test. Analysis was done using Instat GraphPad version 3.1. Multivariate chi square test was used to evaluate association of variable factors with anaemia. Variables with $\mathrm{p}$ value $<0.05$ were considered statistically significant.

\section{Results}

A total of 200 anemic women were included in the study. $70 \%$ were antenatal cases, $30 \%$ non antenatal including (abortion cases, gynecology-cases, postpartum cases). Maximum (99\%) participants were housewives, 1\% were unmarried. Majority of the cases were less than 20 yrs of age. More than 80 cases were married at early age and had 1 child before 20 years of age. Most of the women (85\%) were unaware of their anemic condition. Participants reported various socio demographic, obstetrical factors as indicated in table 1 . Using multivariate analysis, the sociodemographic factors like age, age at marriage, age at first child birth $(\mathrm{p}<0.0001)$, illiteracy $(\mathrm{p}<0.0017)$, multiparity showed a significant association with risk of anaemia $(\mathrm{p}<0.0029)$, as indicated in table 1 .

Moderate degree of anaemia mainly found in pregnant women. On the other hand, non pregnant women mostly presented with severe anaemia, as shown in table 2 .

Among pregnant women, $47 \%$ of cases no able to attend a single antenatal visit as shown in table 3 . Only $6 \%$ of the 
The New Indian Journal of OBGYN. 2021 (January-June);7(2)

women used contraception (any method - 11 among antenatal, 1 among non antenatal).

Table 1: Analysis of sociodemographic, obstetrical factors associated with anaemia $(\mathbf{N}=\mathbf{2 0 0})$

\begin{tabular}{|c|c|c|c|c|}
\hline Variables & Categories & $\begin{array}{l}\text { Antenatal } \\
(n=140) \\
\text { cases }(\%)\end{array}$ & $\begin{array}{l}\text { Non- } \\
\text { antenatal } \\
(n=60) \\
\text { cases }(\%)\end{array}$ & P value \\
\hline $\begin{array}{l}\text { Age } \\
\text { (years) }\end{array}$ & $\begin{array}{l}<20 \\
21-25 \\
26-30 \\
31-35 \\
35-40 \\
>40 \\
\end{array}$ & $\begin{array}{l}56(40 \%) \\
26(18.57 \%) \\
28(20 \%) \\
2(1.42 \%) \\
- \\
-\end{array}$ & $\begin{array}{l}34(56.66 \%) \\
4(6.66 \%) \\
4(6.66 \%) \\
20(33.33 \%) \\
22(36.66 \%) \\
4(6.66 \%) \\
\end{array}$ & $\begin{array}{l}X^{2}=78.489 \\
D O F=5, P \\
\text { value }<0.0001\end{array}$ \\
\hline $\begin{array}{l}\text { Age at } \\
\text { marriage } \\
\text { (years) }\end{array}$ & $\begin{array}{l}<20 \\
21-25 \\
26-30 \\
>30 \\
\end{array}$ & $\begin{array}{l}81(57.85 \%) \\
64(45.71 \%) \\
22(15.71 \%) \\
2(5.71 \%) \\
\end{array}$ & $\begin{array}{l}5(8.33 \%) \\
4(6.66 \%) \\
11(18.33 \%) \\
11(18.33 \%) \\
\end{array}$ & $\begin{array}{l}\mathrm{X}^{2}=66.389 \\
\mathrm{DOF}=3, \mathrm{P} \\
\text { value }<0.0001\end{array}$ \\
\hline $\begin{array}{l}\text { Age at } \\
\text { first } \\
\text { childbirth } \\
\text { (years) }\end{array}$ & $\begin{array}{l}<20 \\
21-25 \\
26-30 \\
>30\end{array}$ & $\begin{array}{l}84(60 \%) \\
46(32.85 \%) \\
45(32.84 \%) \\
1(0.71 \%) \\
\end{array}$ & $\begin{array}{l}2(3.33 \%) \\
4(6.66 \%) \\
9(15 \%) \\
8(13.33 \%) \\
\end{array}$ & $\begin{array}{l}\mathrm{X}^{2}=61.821 \\
\mathrm{DOF}=3, \mathrm{P} \\
\text { value }<0.0001\end{array}$ \\
\hline Education & $\begin{array}{l}\text { Primary } \\
\text { education } \\
\text { Illiterate }\end{array}$ & $\begin{array}{l}20(14.28 \%) \\
126(90 \%)\end{array}$ & $\begin{array}{l}18(30 \%) \\
36(60 \%) \\
\end{array}$ & $\begin{array}{l}\mathrm{X}^{2}=9.875 \\
\mathrm{DOF}=1, \mathrm{P} \\
\text { value }=0.0017\end{array}$ \\
\hline Parity & $\begin{array}{l}1-2 \\
>3\end{array}$ & $\begin{array}{l}64(45.71 \%) \\
76(54.28 \%)\end{array}$ & $\begin{array}{l}14(23.33 \%) \\
46(76.66 \%)\end{array}$ & $\begin{array}{l}\mathrm{X}^{2}=8.843 \\
\mathrm{DOF}=1, \mathrm{P} \\
\text { value }=0.0029\end{array}$ \\
\hline
\end{tabular}

Regarding outcome of pregnancy, 22 cases (out of 140 antenatal) associated with prematurity, 64 cases with low birth weight, and 18 cases with early neonatal death. Out of 140 cases, 7 maternal deaths were noted, as shown in table 4.

Table 2: Degree of anaemia among antenatal and non antenatal women

\begin{tabular}{|c|c|c|c|}
\hline \multirow[t]{2}{*}{ Parameters } & \multirow[t]{2}{*}{ Degree } & \multicolumn{2}{|c|}{ Anemic women $(n=200)$} \\
\hline & & $\begin{array}{l}\text { Antenatal cases } \\
(\%)(n=140)\end{array}$ & $\begin{array}{l}\text { Non-antenatal } \\
\text { cases }(\%)(n=60)\end{array}$ \\
\hline \multirow{3}{*}{$\begin{array}{l}\text { Degree of } \\
\text { anaemia }\end{array}$} & Mild & $15(10.71 \%)$ & $11(18.33 \%)$ \\
\hline & Moderate & $86(61.42 \%)$ & $14(23.33 \%)$ \\
\hline & Severe & $18(12.85 \%)$ & $56(93.33 \%)$ \\
\hline
\end{tabular}

Table 3: Frequency of antenatal visit and use of contraception

\begin{tabular}{lll}
\hline Parameters & Category & Number (\%) \\
\hline No of antenatal visit & 0 & $66(47 \%)$ \\
& 1 & $52(37 \%)$ \\
& 2 & $12(9 \%)$ \\
Use of contraception & 3 & $10(7 \%)$ \\
& Antenatal & $11(7.85 \%)$ \\
& Non antenatal & $1(1.67 \%)$ \\
\hline
\end{tabular}

\begin{tabular}{lc} 
Table 4: Fetomaternal outcome of antenatal cases $(\mathbf{N}=\mathbf{1 4 0})$ \\
\hline Parameters & Number $(\%)$ \\
\hline Preterm delivery & $22(15.7 \%)$ \\
Low birth weight baby & $64(45.71 \%)$ \\
Early neonatal death & $18(12.85 \%)$ \\
Maternal mortality & $7(0.05 \%)$ \\
\hline
\end{tabular}

Most of the women (95\%) were undergone anaemia correction in which parenteral iron therapy followed by blood transfusion was the main mode of anaemia correction in antenatal cases and blood transfusion in non antenatal cases. $(5 \%)$ include incomplete or no correction, as indicated in table 5 .

Table 5: Mode of treatment

\begin{tabular}{llll}
\hline Mode of treatment & \multicolumn{2}{l}{ Number of anemic women (N=200) } & \multirow{2}{*}{ Total } \\
\cline { 2 - 3 } & $\begin{array}{l}\text { Antenatal } \\
\text { cases (\%) }\end{array}$ & $\begin{array}{l}\text { Non antenatal } \\
\text { cases (\%) }\end{array}$ & \\
\hline Blood transfusion & $40(28 \%)$ & $49(81 \%)$ & $89(45 \%)$ \\
Iron sucrose & $55(39 \%)$ & $3(5 \%)$ & $58(29 \%)$ \\
Both & $39(28 \%)$ & $4(6 \%)$ & $43(21 \%)$ \\
\hline
\end{tabular}

\section{Discussion}

The demographic characteristics of antenatal and non antenatal women are summarised in table 1. Majority $90 \%$ of the women were Muslims and Hindus (10\%). Based upon the criteria to classify degree of anaemia by ${ }^{10} \mathrm{WHO}$, out of all anaemic women, in table 2, majority of them in this study had either moderate or severe anaemia. Moderate degree of anaemia was more common in antenatal cases and non antenatal women mainly presented with severe anaemia. Thus, moderate anaemia was more prevalent compared to other degree of anaemia. Regarding severity the result of present study was similar to the result of study conducted at ${ }^{11}$ Kamrup Assam in 2014.

As shown in table 1, anaemic cases were more in younger age group (less than 20 year) indicates that teenage are more prone to anaemia and nutritional status is poor and little attention was paid to correct anaemia in pre pregnancy period. This result was similar to the results of study ${ }^{7}$ conducted at Gauhati medical college, Assam in (2015). Regarding age at marriage and first child birth $43-44 \%$ of women were married at early age and had child before 20 years of age. The results regarding the literacy rate in our study (table 1) are quite discouraging. Out of 200 cases $162(81 \%)$ were illiterate while rest $38(19 \%)$ were only primary education. Among women having higher education anaemia was found to be less severe. Table 1, shows a significant association of anaemia with illiteracy ( $p$ $<0.0017)$. The most important finding was no antenatal visits among $47 \%$ of anaemic women. One of the reason, that anaemia was not corrected early. Severity of anaemia seems to be increased with number of abortions, as most of the induced abortions presented with low $\mathrm{Hb}$ values (severe anaemia).The study also found that women with induced abortions were > para 3 (up to 6), which indicates less knowledge and acceptance regarding contraception among women. Only $6 \%$ of the women used contraception (any method 11among antenatal, 1 among nonantenatal). It was observed in our study that anaemia was more associated with 
The New Indian Journal of OBGYN. 2021 (January-June);7(2)

early marriage, early child birth $(\mathrm{p}<0.0001)$, and illiteracy $(\mathrm{p}<0.0017)$, multiparty $(\mathrm{p}<0.0029)($ table 1$)$.

$95 \%$ of the women at FAAMCH were undergone correction either through blood transfusion (45\%), Fesucrose along with (oral iron therapy twice daily) (29\%) or both $(21 \%),(5 \%)$ include incomplete or no correction due to unavailability of blood donor, patient attendant not able to arrange blood, unavailability of blood of particular blood group, leave against medical advice. These women discharged with oral iron therapy at home. Parenteral iron therapy followed by blood transfusion was the main mode of anaemia correction in antenatal cases and blood transfusion in non antenatal cases.

Regarding outcome of pregnancy, 22 cases (out of 140 antenatal) associated with prematurity, 64 cases with low birth weight, 18 cases with early neonatal death. Results were similar to the results of ${ }^{12}$ study conducted in 2013. Out of 200, 7 maternal deaths were noted.

Limitations of the study: Facility for spectrophotometric analysis of $\mathrm{Hb}$ and serum iron studies was not available, so hemoglobinopathies could not be ruled out and the confirmation of iron deficiency was not done. We assumed that all the include patients were suffering from iron deficiency anaemia. As iron deficiency anaemia is most common type of anaemia in Indian women and pregnancy.

\section{Conclusion}

Our study revealed young age, early marriage, early child birth, multiparity, short spacing of children, illiteracy and late antenatal booking, reluctance for contraception responsible for severity of anaemia in women. In our study, anaemia was associated with increased risk of prematurity and low birth weight babies and early neonatal death in pregnant women and mortality and morbidity in non pregnant women. Parenteral iron therapy followed by blood transfusion was the main mode of anaemia correction in antenatal cases and blood transfusion in non antenatal cases.

\section{Conflict of interest: None. Disclaimer: Nil.}

\section{References}

1. WHO. Anaemia [Internet]. Geneva: WHO; 2020 [cited on February 2020]. Available form: http://www. who.int/topics/anaemia/en/.

2. WHO. The global prevalence of anaemia. WHO Global Database on Anaemia. Geneva, Switzerland: WHO global database on anaemia; 2015.
3. WHO. Daily iron supplement in adult women and adolescent girls [Internet]. Geneva: WHO; 2016 [cited on February 2020]. Available from: https://www. who.int.elena.titles.

4. International institute of population sciences. National family health survey, India - 4 facts sheets. Mumbai: IIPS; 2015.

5. International institute of population sciences. NFHS 2015 - 2016 (NFHS-4) 2016a. Mumbai: IIPS; 2016. Available from: http://www.rchiips.org /NFHS/pdf/nfhs 4/India.pdf.

6. Mousumi G, Ranjan KP. Maternal anaemia Pregnancy, Complications and Birth outcome: Evidence from N-E India. Journal of N-E studies. 2013; 3(1): 74-85.

7. Bora G, Barman S, Barman JD. Maternal anaemia - A prevailing burden in Assam, India. IOCR Journal of Dental and medical Sciences (IOSR-JDMS). 2015; 14(3): 42-7.

8. IIPS. NFHS - 3 Fact sheets. Mumbai: IIPS; 2005.

9. Lokare PO, Karanjekar VD, Gattani PL, Kulkarni AP. A study of prevalence of anaemia and socioeconomic factors, associated with anaemia in pregnant in Aurangabad city, India. Annuals of Nigerian Medicine, 2012; 6: 30-4.

10. WHO. Haemoglobin concentrations for the diagnosis of anaemia and assessment of severity. Geneva: WHO; 2011.

11. Biswas M, Baruah R. Maternal anaemia associated with Sociodemographic factors among Pregnant Women of Boko-Bongaon Kamrup, Assam. Indian Journal of Basic and Applied Medical Research. 2014; 3(2): 712-21.

12. Kumar KJ, Asha N, Murthy DS, Sujatha M, Manjunath VG. Maternal anaemia in various trimesters and its effect on newborn weight and maturity: An observational study. Int J Prev Med. 2013 Feb; 4(2): 193-9.

\footnotetext{
Manideepa Roy ${ }^{1}$, Geeta Chauhan ${ }^{2}$

${ }^{1}$ Assistant Professor, Department of Obstetrics and Gynaecology, FAA Medical College, Barpeta, Assam, India; ${ }^{2}$ Post Graduate Student, Department of Obstetrics and Gynaecology, FAA Medical College, Barpeta, Assam, India.
} 